\title{
Personality Types and Development of Adolescents' Conflict with Friends
}

\author{
RONGQIN YU*, SUSAN J. T. BRANJE, LOES KEIJSERS and WIM H. J. MEEUS \\ Research Centre Adolescent Development, Utrecht University, Utrecht, Netherlands
}

\begin{abstract}
This study examined the development of adolescents' conflict frequency and conflict resolution with their best friends, and tested whether adolescents with different personality types differed in these developmental changes from early to middle adolescence. Dutch adolescents $\left(N=922,468\right.$ boys; $M_{\text {age }}=12.4$ years at first wave $)$ annually filled in questionnaires for five consecutive years. Growth modelling revealed that, whereas adolescents' conflict frequency and hostile conflict resolution did not change, positive problem solving, withdrawal, and compliance during conflict with best friends increased from age 12 to 16 years. Adolescents with different personality types differed in the mean levels of conflict frequency and conflict resolution strategies. That is, resilients had less conflict with friends than undercontrollers and overcontrollers. During conflict, resilients used the least hostile conflict resolution and compliance, and employed the most positive problem solving. Undercontrollers adopted the least positive problem solving, and overcontrollers complied and withdrew the most. Using a person-centred approach, three developmental conflict resolution types were identified based on different constellations of the four conflict resolution strategies over time. Adolescents with different personality types had different distributions on the conflict resolution types. Copyright (C) 2013 John Wiley \& Sons, Ltd.
\end{abstract}

Key words: conflict resolution; conflict frequency; development; personality types; best friends

During adolescence, friendships become increasingly more intimate, equal, and reciprocal (De Goede, Branje, \& Meeus, 2009; Furman \& Buhrmester, 1992; Hartup, 1993). Additionally, adolescent friends are increasingly able to show mutual respect for each others' individuality (Selfhout, Branje, \& Meeus, 2009; Shulman \& Knafo, 1997). These developments may lead to changes in how adolescents experience and resolve conflicts with their friends. Current evidence on age-related changes in conflicts among friends, such as conflict frequency and conflict resolution, is based predominantly on cross-sectional comparisons, however. Moreover, there might be heterogeneity in the development of conflict frequency and conflict resolution with friends, depending on individuals' personality. Indeed, others have suggested that personality could affect an individual's manner of handling conflict through various motivational, cognitive, and affective processes (Park \& Antonioni, 2007). This study aimed to examine the developmental pattern of adolescents' conflict frequency and conflict resolution with their best friends, and differences in these developmental changes between individuals with different personality types.

Conflict frequency entails the number of disagreements or quarrels in a certain period, and conflict resolution involves the strategy an individual uses to handle such disputes (Laursen, 1998). Theoretically speaking, various conflict resolution strategies have been distinguished. According to the Dual Concern model (Pruitt \& Carnevale,

*Correspondence to: Rongqin Yu, Research Centre Adolescent Development, Utrecht University, Utrecht, Netherlands.

E-mail: R.YU@UU.NL
1993), individuals' utilization of conflict resolution depends on the level of concern for oneself versus others. Specifically, collaboration occurs when there is high concern for both oneself and others. This strategy is characterized by positive conflict resolution behaviours such as negotiation and compromise. Accommodation takes place when there is high concern for others, but low concern for oneself. This strategy is characterized by high levels of compliance. A controlling resolution strategy reflects a high concern for oneself and low concern for others, and is characterized by negative affect, hostility, or coercive behaviour. In addition, a nonconfrontational strategy, which involves reducing the importance of conflict and attempting to suppress thinking about conflict, represents a low concern for both oneself and others. This strategy is characterized by avoidant and withdrawing behaviours. These four conflict resolution strategies are widely recognized in the adolescent-friend literature (Laursen, Finkelstein, \& Betts, 2001).

\section{Development of Conflict Frequency and Conflict Resolution with Best Friends}

Friendships undergo essential developmental changes during adolescence that may have important implications for adolescents' conflict frequency and conflict resolution with friends. In particular, closeness and intimacy in adolescents' friendships increase (De Goede et al., 2009; Hartup, 1993), and adolescents are progressively more able to balance closeness and individuality with friends (Laursen et al., 2001; Selfhout et al., 2009; Shulman \& Knafo, 1997). Further, friends become important interpersonal resources during adolescence 
(Brown, 2004; Laursen \& Pursell, 2008). These developmental changes spur the understanding and consideration of others' needs, and permit self-interest to be subordinated to the interests of others (Laursen et al., 2001; Selfhout et al., 2009). These advances also increasingly motivate adolescents to avoid harming their friendships, which are vulnerable to disruption due to their voluntary and egalitarian nature (Laursen, 1998; Laursen \& Pursell, 2008). As a result, adolescents are likely to be gradually more adept at taking the perspective of others and at being aware of the potential disruption that conflict can pose to their friendship. These changes may result in a decline of conflict frequency with friends over time. When conflicts do occur, adolescents might decreasingly use hostile conflict resolution behaviours focused only on self needs, which might lead to a breakup of the friendship. Instead, they may increasingly adopt strategies that reflect others' needs and/or avoid friendship disruption, such as positive problem solving, compliance, and withdrawal (Bowker, 2004; Laursen, 1998). Indeed, with the gradual development of social cognitive abilities, adolescents employ more positive problem solving during conflict (Dunn, 1993; Sandy \& Cochran, 2000).

Cross-sectional research has offered some suggestions regarding the development of conflict frequency and conflict resolution in friendships during adolescence. Some research has shown that conflict frequency did not differ among cohorts with different mean ages from late childhood to early adolescence (i.e. from 8 to 14 years; Berndt \& Perry, 1986). In contrast, another study found lower conflict frequency with friends in adolescents aged 15 and 19 years than in younger children and adolescents with mean ages of 9 and 12 years (Furman \& Buhrmester, 1992). For conflict resolution strategies, a systematic meta-analytic review comparing studies among cohorts of children, adolescents, and young adults revealed that older cohorts use higher levels of positive problem solving and withdrawal, and lower levels of hostile conflict resolution (Laursen et al., 2001). Longitudinal studies examining developmental changes of conflict frequency and conflict resolution in adolescent friendships are lacking, however.

Taking together the aforementioned theoretical ideas and cross-sectional findings, conflict frequency with friends should decline during adolescence. Additionally, adolescents should use less hostile conflict resolution and more positive problem solving, withdrawal, and compliance as they age. Longitudinal studies are clearly needed to confirm these assumptions.

Conflict resolution types. Different conflict resolution strategies are not used in isolation, but instead can be combined to form particular patterns. In another words, different persons may use different combinations of conflict resolution strategies, which distinguish them from one another (Branje, Van Doorn, Van der Valk, \& Meeus, 2009). For instance, it has been found that when in conflict with parents, some adolescents typically used a positive conflict resolution strategy and seldom used withdraw or hostile conflict resolution strategy, whereas some adolescents adopted mainly hostile conflict resolution strategy, withdraw, or compliance, and some adolescents tended to not use any conflict resolution strategies. More interestingly, the combination of styles may determine the effect of individual styles. For instance, when withdrawal was the only strategy used to resolve conflicts with parents, conflict frequency was more strongly related to delinquency, but when withdrawal was used in combination with hostile conflict resolution, conflict frequency was more strongly related to depression (Branje et al., 2009). In this study, we therefore, by using a person-centred approach, attempted to identify whether different groups of adolescents had different constellations of conflict resolution strategies with their best friends, in terms of mean levels and developmental changes. Subsequently, we explored whether adolescents with different configurations of conflict resolution strategies differed in levels and developmental changes of conflict frequency.

\section{Personality Characteristics and Conflict}

Conflict frequency and conflict resolution may vary as a function of personality. People with different personality characteristics have different motivations in interpersonal relations, perceive the same conflict situation differently, or experience different affects when engaging in similar behaviours. As a result, they might rely on different conflict resolution strategies (Garaziano, Jensen-Campbell, \& Hair, 1996; Moskowitz \& Coté, 1995; Park \& Antonioni, 2007).

Prior studies investigating relations between personality characteristics and adolescents' conflict resolution strategies predominantly employed a variable-centred approach, with which relations between a certain personality dimension and conflict resolution strategies were examined across persons in a specific population. An important and necessary complement to the variable-centred approach is a personcentred approach, especially in studies involving personality (Donnellan \& Robins, 2010; Meeus, Van de Schoot, Klimstra, \& Branje, 2011). With a person-centred approach, the common within-person structure of personality is examined (Mervielde \& Asendorpf, 2000). Thus, in our study, we examined whether adolescents with different personality types, or with different configuration of personality traits, differed in the development of adolescents' conflict frequency and conflict resolution strategies.

The most commonly used person-centred approach to personality was proposed by Block and Block (1980). Three major personality types-overcontrollers, undercontrollers, and resilients - are consistently identified by using different methods such as Q factor analysis, cluster analysis, and latent class (growth) analysis on data from different informants ranging from caregivers reporting, to self-reporting, and to behavioural ratings. Moreover, these three personality types emerged in samples across childhood to adulthood from various countries such as Italy, Germany, the Netherlands, Spain, and the USA (Block \& Block, 1980; Caspi \& Silva, 1995; Hart, Hoffman, Edelstein, \& Keller, 1997; Klimstra, Hale, Raaijmakers, Branje, \& Meeus, 2010; Meeus et al., 2011; Robins, John, Caspi, Moffitt, \& Stouthamer-Loeber, 1996). In addition, studies using cluster analysis of 
questionnaires assessing Big Five personality traits have shown that a three-cluster solution proved to be the most replicable (Asendorpf \& van Aken, 1999). Namely, these three personality types were reliably distinguished in Big Five personality traits. Specifically, undercontrollers are characterized by low conscientiousness and agreeableness, resilients have generally high scores on all five dimensions, and overcontrollers typically have low emotional stability, low extraversion, and are comparably agreeable as resilients (Klimstra et al., 2010; Robins et al., 1996). No research has investigated whether individuals with different personality types differ in levels of or developmental changes in conflict frequency and conflict resolution with friends, although there is some indirect evidence suggesting differences.

In terms of conflict frequency, studies have found that both undercontrollers and overcontrollers are more likely to be involved in conflict with household members (i.e. common residents in the same house) in early adulthood. They are also more likely to be fired due to conflictual interpersonal relationships in the work place (Caspi, 2000; Newman, Caspi, Moffitt, \& Silva, 1997). In light of these results, we expect undercontrolling and overcontrolling adolescents to report more conflict in friendships than resilient adolescents.

Adolescents with different personality types may also vary in levels and development of conflict resolution behaviours with friends. A personality factor closely related to conflict resolution is agreeableness, as it entails motives for maintaining positive interpersonal relationships (Jensen-Campbell \& Graziano, 2001). More agreeable persons can better regulate their anger, approach conflicts with less negative affect, and are more likely to use positive problem-solving strategies (Garaziano et al., 1996; Jensen-Campbell, Graziano, \& Hair, 1996; Park \& Antonioni, 2007). Thus, undercontrollers' low agreeableness might promote them to use more hostile conflict resolution and less positive problem solving than overcontrollers and resilients. In line with this expectation, undercontrollers appear to be more coercive and aggressive in social situations than overcontrollers and resilients (Denissen, Asendorpf, \& Van Aken, 2007). Although undercontrollers are expected to use most hostile conflict resolution, overcontrollers' low emotional stability may make them react to stressful events such as conflict with more maladaptive strategies (e.g. hostile strategies) than resilients (Gunthert, Cohen, \& Armeli, 1999).

Several findings suggest that overcontrollers may be most likely to show withdrawal and compliance in conflicts with friends. Overcontrollers often keep thoughts and feelings to themselves (Hart et al., 1997), and their social withdrawal level is higher than that of undercontrollers and resilients (Scholte, Van Lieshout, De Wit, \& Van Aken, 2005). They are often described as compliant and indecisive, and tend to give in during conflicts (Asendorpf \& Van Aken, 1999; Hart et al., 1997). In contrast, resilients are particularly forceful and assertive, and are more likely to take up leadership roles (Caspi \& Silva, 1995). Although more agreeable persons have been found to also use more withdrawal and compliance in conflicts (Garaziano et al., 1996; Jensen-Campbell et al., 1996; Park \& Antonioni, 2007), which would suggest lower levels of compliance and withdrawal for undercontrollers than for resilients and overcontrollers, we also expect that overcontrollers withdraw and comply more than undercontrollers and resilients.

In addition to the differences between personality types in the level of conflict frequency and conflict resolution, we also explored the differences between types in the development in conflict frequency and conflict resolution. Further, we explored the relation between the typology of conflict resolution and the personality types.

\section{The Current Study}

In the present study, we followed a group of adolescents from early to middle adolescence in order to address the following research questions: (1) How do conflict frequency and conflict resolution with best friends develop during this period? (2) Are there different developmental types of conflict resolution with friends? (3) Whether adolescents with different personality types differed in the development of adolescents' conflict frequency and conflict resolution? (4) Is adolescents' conflict resolution type related to their personality type?

\section{METHOD}

\section{Participants}

Participants in this study were 922 adolescents [468 boys; $M_{\text {age }}=12.4$ years $(S D=.58)$ at first measurement $]$ from the young adolescent cohort participating in CONAMORE (CONflict And Management Of Relationships; Meeus et al., 2006) longitudinal study. Participants were recruited from various randomly selected high schools in the province of Utrecht, the Netherlands. The sample covered a broad range of education levels. Most of the participants in the current study identified themselves as Dutch $(83.4 \%)$. The other $16.6 \%$ participants indicated that they belonged to ethnic minorities (e.g. Surinamese, Moroccan, or Turkish). Dutch youth were slightly over-represented in this sample, because ethnic minorities compose $21 \%$ of the general Dutch adolescent population (Statistics Netherlands, 2008).

The 922 participants came from the original sample of 923 adolescents. One case could not be included in the analyses, because this adolescent reported to have no friend in all waves and therefore had completely missing data on conflict frequency and conflict resolution across waves. Sample attrition in the original sample was very low: Over the five measurement waves, the number of participants in waves 1 , 2, 3, 4, and 5 was 923, 923, 923, 923, and 913, respectively. For personality, across five waves, $5.2 \%$ of the data was missing, and these missing data were estimated using Expectation Maximization imputation (EM) in SPSS (SPSS Inc., Chicago, Illinois, USA). For conflict frequency and conflict resolution strategies, a maximum of $4.7 \%$ of the cases was missing per variable. Little's Missing Completely at Random (MCAR) test (Little, 1988) on all variables used in this study (i.e. personality types, gender, conflict frequency, and conflict resolution strategies) indicated that the pattern of missing 
values was completely at random $\left[\chi^{2}(N=922,718)=692.77\right.$, $p=.74]$. Thus, we included respondents with missing values in our analyses using a Full Information Maximum Likelihood procedure (Enders \& Bandalos, 2001), within the program Mplus 6 (Muthén \& Muthén, 2010). Robust maximum likelihood was used in the estimation.

\section{Procedure}

An invitation letter and a description of the study were sent to adolescents' home addresses. Both adolescents and their parents provided informed consent for the adolescents' participation. Less than $1.0 \%$ of the contacted subjects decided not to participate. Adolescents annually filled in various questionnaires at school after school hours. Trained research assistants gave verbal instructions about filling out the questionnaire besides written instructions along with the questionnaires. Confidentiality was assured explicitly before participation. Participants received $€ 10$ as a reward for their participation in each wave.

\section{Measures}

Conflict frequency. Conflict frequency was assessed with the Dutch translation of the Interpersonal Conflict Questionnaire (Laursen, 1993). It has 35 items covering potential conflict topics with a 5-point Likert scale, ranging from 1 (never) to 5 (often). Adolescents reported on how often they had conflicts, disagreements, or quarrels with their best friends regarding a specific topic during the last week. Sample items are 'Sex, intimacy and relationships' and 'Criticism towards friends with whom you associate'. Average conflict scores were obtained by averaging the scores across these 35 items. Adequate validity has been reported for this scale (Laursen, 1993). In the current study, Cronbach's alphas ranged from .96 to .98 across waves, indicating good reliability.

Conflict resolution. Conflict resolution of adolescents with their best friends was assessed with a Dutch adaptation of Kurdek's Conflict Resolution Style Inventory (Kurdek, 1994; Van Doorn, Branje, \& Meeus, 2007). This inventory measures four conflict resolution strategies, including conflict engagement (indicating hostile conflict resolution), positive problem solving, withdrawal, and compliance. Each conflict resolution strategy was measured by five items. Sample items were as follows: for hostile conflict resolution: 'attacking him or her personally', for positive problem solving: 'negotiating and trying to find a solution that is mutually acceptable', for withdrawal: 'keep my mouth shut for a long time', and for compliance: 'not defending my opinion'. Adolescents reported their conflict resolution on a 5-point Likert scale ranging from 1 (never) to 5 (always). Studies have indicated that the Conflict Resolution Style Inventory has a good internal consistency, a good 1-year stability, and moderate convergent, concurrent, and predictive validity (Kurdek, 1994). Across five waves, Cronbach's alphas in this study ranged from .79 to .80 for hostile conflict resolution, .82 to .91 for positive problem solving, .82 to .84 for withdrawal, and .68 to .77 for compliance.

Adolescents' personality types. Adolescents' personality was assessed annually for 5 years with the Quick Big Five questionnaire (Goldberg, 1992; Vermulst \& Gerris, 2005). Thirty personality makers were used to assess five personality dimensions (each with six items): Extraversion (e.g. 'talkative'), Agreeableness (e.g. 'sympathetic'), Conscientiousness (e.g. 'systematic'), Neuroticism (e.g. 'worried', reverse-scored), and Openness to experience (e.g. 'creative'). Adolescents rated their personality on a 7-point Likert scale ranging from 1 (very untrue) to 7 (very true). Studies have reported adequate reliability and validity of this scale (e.g. Branje, Van Lieshout, \& Gerris, 2007). Cronbach's alphas ranged from .76 to .88 across the five waves in this study.

Early studies have shown that Block and Block's (1980) three personality types (i.e. overcontrollers, undercontrollers, and resilients) can be constructed directly from the Big Five dimensions (Robins et al., 1996). We used this classification of personality types, which was established in a prior study (Klimstra et al., 2010) that used a 99.9\% identical sample (i.e. 923 instead of 922 cases) and the same five measurement waves as the current study. To incorporate the normative developmental changes in personality during adolescence, this prior study applied Latent Class Growth Analysis (LCGA; Nagin, 2005) to constitute the three developmental personality types. Specifically, with this developmental approach, among 923 adolescents, 382 (41.39\%) were classified as overcontrollers, $228(24.70 \%)$ as undercontrollers, and 313 (33.91\%) as resilients. Resilients scored moderate to high on all Big Five dimensions, overcontrollers scored particularly low on extraversion and emotional stability, and undercontrollers had low consciousness and agreeableness. (For details of the mean scores of Big Five personality traits for these three personality types, please see Klimstra et al., 2010.) This classification of personality types, taking into account the normative development of personality, was also used for the current study, with one less resilients than the original sample.

\section{Strategy of Analyses}

First, to examine developmental changes of adolescents' conflict with friends, Latent Growth Modelling (Duncan, Duncan, Strycker, Li, \& Alpert, 1999) in Mplus 6 (Muthén \& Muthén, 2010) was conducted for conflict frequency and each of the four conflict resolution strategies, separately. Both linear and quadratic models were tested and compared with Bayesian Information Criterion (BIC). A model with lower BIC value was preferred because a lower BIC indicates that the model has a better fit to the data (Raftery, 1993). To evaluate the goodness of model fit, we used multiple criteria: comparative fit index (CFI), root mean squared error of approximation (RMSEA), and standard root mean square residual (SRMR). For CFIs, values of .95 indicate good fit (Hu \& Bentler, 1999). RMSEA and SRMR values up to .08 represent an acceptable fit (Bollen, 1989; Kline, 2005).

Second, to investigate whether there were different groups of adolescents who used distinct constellations of 
conflict resolution strategies, an LCGA was conducted. LCGA is a technique that identifies the smallest number of classes capturing the most variance among individuals in initial level (i.e. intercept) and change rate (i.e. slope) on a certain set of variables. To determine the model with the optimal number of latent classes, we employed multiple criteria. First, we used the Sample Size Adjusted Bayesian Information Criterion (SSA-BIC; Schwarz, 1978) and the Lo-Mendell-Rubin Likelihood Ratio Test (LMR-LRT; Lo, Mendell, \& Rubin, 2001). The optimal model has the lowest SSA-BIC, while a significant LMR-LRT indicates that a model with $k$ classes is better than a model with $k-1$ classes. Second, the theoretical meaningfulness of a class should be acceptable. That is, if an additional class is only a slight variation of a previously extracted class, the most parsimonious solution should be chosen (Muthén \& Muthén, 2000). In addition, we checked whether the model had adequate entropy, which indicates classification accuracy. It ranges from .00 to 1.00 , with higher figures indicating a more accurate classification (Hix-Small, Duncan, Duncan, \& Okut, 2004). Subsequently, we estimated whether adolescents with different conflict resolution types differed in conflict frequency by regressing the intercept and slope of conflict frequency on the conflict resolution typology, while controlling for gender.

Third, we tested the role of personality types in the levels of and developmental changes in conflict frequency and conflict resolution with best friends. That is, we tested whether adolescents' with different personality types differed in the levels or the development of conflict frequency and conflict resolution. For that purpose, the intercepts and slopes of conflict frequency and each conflict resolution strategy were regressed on the personality types. We used dummy variables for personality types. First, to compare the effect of undercontrollers versus resilients and the effect of overcontrollers versus resilients, we included the three personality types as two dummy variables with the resilient personality type as a reference category. In addition, to test the difference between overcontrollers and undercontrollers, we repeated the analyses with a second set of dummy variables, in which we coded the overcontrollers as the reference category. We also controlled for gender by regressing the intercepts and slopes of conflict frequency and each conflict resolution strategy on adolescents' gender.

Fourth, we used chi-square tests to examine whether adolescents with different personality types had different conflict resolution types. If the chi-square test indicated a significant difference in distribution, the adjusted residual value $\left(Z_{\text {adj }}\right)$ was calculated to determine which cells of the chi-square contingency table contributed to the significant effect. $Z_{\text {adj }}$ of higher than 2 or less than -2 indicates that the observed count of a variable in one cell of the chi-square contingency table is significantly higher or lower than the expected count, respectively (Haberman, 1973).

\section{RESULTS}

\section{Descriptive Statistics and Development of Conflict Frequency and Conflict Resolution Strategies}

The means and standard deviations of conflict frequency and the four conflict resolution strategies across five annual waves are shown in Table 1.

To investigate the developmental changes in conflict frequency and in the four conflict resolution strategies, we conducted univariate LGAs. All linear models provided an acceptable fit to our data (i.e. CFIs were higher than .95 , and RMSEA and SRMR were lower than .08). Moreover, for conflict frequency and three out of four conflict resolution strategies (i.e. hostile conflict resolution, positive problem solving, and compliance), the BICs for linear models were lower than those for the quadratic models (i.e. BIC differences ranged from 1.00 to 22.00). The BIC of the linear model for withdrawal was two points higher than that of quadratic model. To facilitate the comparability between models across strategies, we chose linear models as our final models for the four conflict resolution strategies. The estimated mean levels (i.e. intercepts) and developmental changes (i.e. slopes) in adolescents' conflict frequency and conflict resolution strategies are presented in Table 2. Generally, we found that adolescents' conflict frequency with their best friends did not change across years. Moreover, from early to middle adolescence, adolescents increased significantly in the use of positive problem solving, withdrawal, and compliance, whereas the use of hostile conflict resolution did not change.

\section{Typology of Conflict Resolution}

We subsequently examined whether we could distinguish adolescents with different constellations of conflict resolution strategies. By using an LCGA, we found a three-class solution to best fit our data. In particular, the SSA-BICs for the models with 1-4 classes were $36428.99,34120.11$, 33180.74 , and 32659.54. Although the SSA-BIC figure

Table 1. Means and standard deviations of conflict frequency and conflict resolution strategies in adolescent-friend relationships

\begin{tabular}{lccccc}
\hline & Time 1 & Time 2 & Time 3 & Time 4 & Time 5 \\
\cline { 2 - 6 } Variable & $M(S D)$ & $M(S D)$ & $M(S D)$ & $M(S D)$ & $M(S D)$ \\
\hline Conflict frequency & $1.33(0.50)$ & $1.35(0.47)$ & $1.32(0.45)$ & $1.32(0.44)$ & $1.31(0.43)$ \\
Hostile conflict resolution & $1.31(0.52)$ & $1.29(0.50)$ & $1.32(0.53)$ & $1.29(0.49)$ & $1.27(0.46)$ \\
Positive problem solving & $2.51(1.21)$ & $2.92(1.08)$ & $2.94(1.09)$ & $3.19(1.04)$ & $3.30(1.02)$ \\
Withdrawal & $1.49(0.67)$ & $1.54(0.64)$ & $1.64(0.71)$ & $1.61(0.69)$ & $1.60(0.64)$ \\
Compliance & $1.48(0.56)$ & $1.57(0.54)$ & $1.60(0.60)$ & $1.60(0.60)$ & $1.61(0.56)$ \\
\hline
\end{tabular}


Table 2. Estimated developmental changes in adolescents' conflict frequency and conflict resolution strategies with best friends

\begin{tabular}{|c|c|c|c|c|c|c|c|c|}
\hline \multirow[b]{2}{*}{ Growth model } & \multicolumn{4}{|c|}{ Intercept } & \multicolumn{4}{|c|}{ Linear slope } \\
\hline & $M$ & $95 \% \mathrm{CI}$ & $S E$ & $\sigma^{2}$ & $M$ & $95 \%$ CI & $S E$ & $\sigma^{2}$ \\
\hline Conflict frequency & $1.34 * * *$ & $1.31-1.37$ & .02 & $.13 * * *$ & -.00 & $-.01-.00$ & .00 & $.01 * * *$ \\
\hline Hostile conflict resolution & $1.31 * * *$ & $1.28-1.34$ & .02 & $.12 * * *$ & -.01 & $-.02-.00$ & .01 & $.01 * * *$ \\
\hline Positive problem solving & $2.63 * * *$ & $2.56-2.70$ & .04 & $.65^{* * *}$ & $.17 * * *$ & $.15-.19$ & .01 & $.02 * * *$ \\
\hline Withdrawal & $1.52 * * *$ & $1.48-1.56$ & .02 & $.18 * * *$ & $.03^{* * *}$ & $.01-.04$ & .01 & $.01 * * *$ \\
\hline Compliance & $1.51 * * *$ & $1.48-1.55$ & .02 & $.11 * * *$ & $.03^{* * *}$ & $.02-.04$ & .01 & $.01 * * *$ \\
\hline
\end{tabular}

Note: CI, confidence interval. $* * * p<.001 . \sigma^{2}$, variance around the means.

for the model with a 4-class solution was lower than the SSA-BIC value for the model with a 3-class solution, the LMR-LRT test indicated that adding a fourth class did not result in an improvement of the model $(p=.39)$. In addition, the 4-class model added a class that was highly comparable to one of the three classes indicated in the three-class model. Moreover, the model for the three-class solution had high entropy (i.e. .85), indicating high classification accuracy. Entropies for models with 2 to 4 classes were $.92, .85$, and .85 , respectively. Therefore, we chose the three-class solution as the final classification.

Table 3 presents the results of this 3 -class model, with the intercepts (i.e. mean levels) and slopes (i.e. change rates) of the conflict resolution strategies for the three resulting conflict resolution types. The latent classes varied in terms of mean levels of the conflict resolution strategies, but not in terms of the developmental changes. The first latent class scored high on hostile conflict resolution, withdrawal, and compliance, and moderate on positive problem solving. Hence, this type was labelled as the ambivalent conflict resolution type, because individuals in this class adopted an aggressive as well as a withdrawing and compliant conflict resolution style. About $19.00 \% \quad(n=175)$ adolescents belonged to this type. The second latent class scored low in all four conflict resolution strategies. Therefore, this type was called the no-resolution type $[39.70 \%(n=366)$ adolescents were grouped in this type]. The third latent class scored high on positive problem solving, low on hostile conflict resolution and withdrawal, and moderate on compliance. Thus, this type was marked as the positive conflict resolution type [41.30\% $(n=381)$ adolescents were classified in this type]. There were gender differences in the prevalence of the three conflict resolution types. In particular, girls were more likely than boys to belong to the positive conflict resolution type $\left[\chi^{2}(N=922,1)=33.70, p=.00, \varphi=.19\right]$, and less likely to be grouped in the no-resolution type $\left[\chi^{2} \quad(N=922\right.$, $1)=14.44, p=.00, \varphi=.13]$ or the ambivalent conflict resolution type $\left[\chi^{2}(N=922,1)=6.50, p=.01, \varphi=.08\right]$.

Conflict resolution types and conflict frequency. We then estimated whether adolescents with different conflict resolution types differed in conflict frequency, by regressing intercept and slope of conflict frequency on the conflict resolution types. We controlled for gender in this model. Our analyses revealed that adolescents with an ambivalent conflict resolution type showed a significantly higher intercept of conflict frequency than those with a no-resolution $[B$ $(\mathrm{CI})=0.41(0.31,0.51), \beta=.57, p=.00]$ or positive conflict resolution type $[B(\mathrm{CI})=0.38(0.28,0.48), \beta=.53, p=.00]$. However, no significant differences were found in the intercepts of conflict frequency between no-resolution and positive conflict resolution types, or in the slopes among the different conflict resolution types. No gender effects existed.

\section{Role of Personality Types on Conflict Frequency and Conflict Resolution}

We tested whether levels and developmental changes of conflict frequency and conflict resolution strategies would

Table 3. Intercepts and slopes of four conflict resolution strategies across three conflict resolution types

\begin{tabular}{|c|c|c|c|}
\hline \multirow{3}{*}{$\begin{array}{l}\text { Estimated growth factors } \\
\text { for conflict resolution } \\
\text { strategies }\end{array}$} & \multicolumn{3}{|c|}{ Conflict resolution types } \\
\hline & Ambivalent conflict resolution type & No-resolution type & Positive conflict resolution type \\
\hline & $M(95 \% \mathrm{CI})$ & $M(95 \% \mathrm{CI})$ & $M(95 \% \mathrm{CI})$ \\
\hline \multicolumn{4}{|l|}{ Intercept } \\
\hline Hostile conflict resolution & $1.84 * * * \mathrm{a}(1.69,1.99)$ & $1.19^{* * \mathrm{~b}}(1.15,1.23)$ & $1.18 * * * \mathrm{~b}(1.15,1.22)$ \\
\hline Positive problem solving & $2.54 * * * \mathrm{~b}(2.38,2.70)$ & $1.92 * * \mathrm{c}(1.82,2.02)$ & $3.35 * * * \mathrm{a}(3.22,3.48)$ \\
\hline Withdrawal & $2.12 * * * \mathrm{a}(1.96,2.29)$ & $1.35^{* * \mathrm{~b}}(1.29,1.40)$ & $1.41 * * * \mathrm{~b}(1.34,1.47)$ \\
\hline Compliance & $1.87 * * * a \mathrm{a}(1.74,1.99)$ & $1.28 * * \mathrm{c}(1.24,1.32)$ & $1.57 * * * \mathrm{~b}(1.52,1.62)$ \\
\hline \multicolumn{4}{|l|}{ Slope } \\
\hline Hostile conflict resolution & $.01^{\mathrm{a}}(-0.04,0.06)$ & $-.00^{\mathrm{a}}(-0.02,0.01)$ & $-.02 * * \mathrm{a}(-0.03,-0.01)$ \\
\hline Positive problem solving & $.11 * * * \mathrm{bc}(0.06,0.16)$ & $.22 * * *^{\mathrm{a}}(0.18,0.26)$ & $.16 * * * \mathrm{ab}(0.12,0.20)$ \\
\hline Withdrawal & $.03^{\mathrm{a}}(-0.02,0.09)$ & $.04 * *^{\mathrm{a}}(0.02,0.07)$ & $.02^{\mathrm{a}}(-0.01,0.04)$ \\
\hline Compliance & $.05 * \mathrm{a}(0.00,0.09)$ & $.03 * * \mathrm{a}(0.01,0.05)$ & $.02 * \mathrm{a}(0.00,0.04)$ \\
\hline
\end{tabular}

Note: Different superscripts within the same row indicate significant differences $(p<.05)$ between different conflict resolution types in different conflict resolution strategies. ${ }^{*} p<.05 ;{ }^{* *} p<.01 ; * * * p<.001$. 
differ for adolescents with different personality types. To this end, we regressed the intercept and slope of conflict frequency and each of the conflict resolution strategies on personality types, while controlling for the effects of gender. Table 4 and Figures 1-5 display these results.

Personality types and conflict frequency. Personality type had a significant effect on conflict frequency. Namely, overcontrollers and undercontrollers reported significantly higher levels of conflict frequency than resilients. However, no significant differences existed in developmental changes in conflict frequency by personality types, nor were there gender effects.

Personality types and conflict resolution strategies. Individuals with different personality types differed in the mean levels of conflict resolution strategies with friends, but not in the developmental changes. In particular, resilients reported significantly less hostile conflict resolution with friends than overcontrollers or undercontrollers, between whom there was no significant difference. Resilient adolescents revealed the highest use of positive problem solving, followed by overcontrollers and finally by undercontrollers. In addition, overcontrollers were significantly more likely to withdraw and comply than both resilients and undercontrollers. There were no significant differences in withdrawal among the latter two types, but undercontrollers reported more compliance than resilients. In addition, there were effects of gender upon mean levels of hostile conflict resolution and positive problem solving, but not for withdrawal and compliance. Boys reported higher levels of hostile conflict resolution and lower levels of positive problem solving, compared with girls. No gender differences existed in change rates of the conflict resolution strategies.

Personality types and conflict resolution types. We subsequently used chi-square tests to examine whether adolescents with different personality types had different conflict resolution types. Table 5 displays the distribution of adolescents with different personality types on each conflict resolution type. Chi-square tests revealed an overall difference in conflict resolution types among personality types $\left[\chi^{2}(N=922,4)=81.92, p=.00, \varphi=.30\right]$. Specifically, overcontrollers were significantly more likely to belong to the ambivalent conflict resolution type $\left(Z_{\mathrm{adj}}=4.01, p=.00\right)$, but less likely to be grouped in the no-solution type $\left(Z_{\text {adj }}=-2.68, p=.01\right)$. Undercontrollers were more likely to the ambivalent conflict resolution type $\left(Z_{\mathrm{adj}}=2.48, p=.01\right)$, and less likely to be grouped in the positive conflict resolution type $\left(Z_{\text {adj }}=-6.54, p=.00\right)$. Resilients were more likely to be categorized in the positive conflict resolution type $\left(Z_{\mathrm{adj}}=6.51, p=.00\right)$ and less likely to be classified in the ambivalent conflict resolution type $\left(Z_{\text {adj }}=-6.43, p=.00\right)$.

\section{DISCUSSION}

In this study, we examined the development of adolescents' conflict frequency and conflict resolution strategies with their be classified in the no-solution type $\left(Z_{\mathrm{adj}}=4.60, p=.00\right)$, or

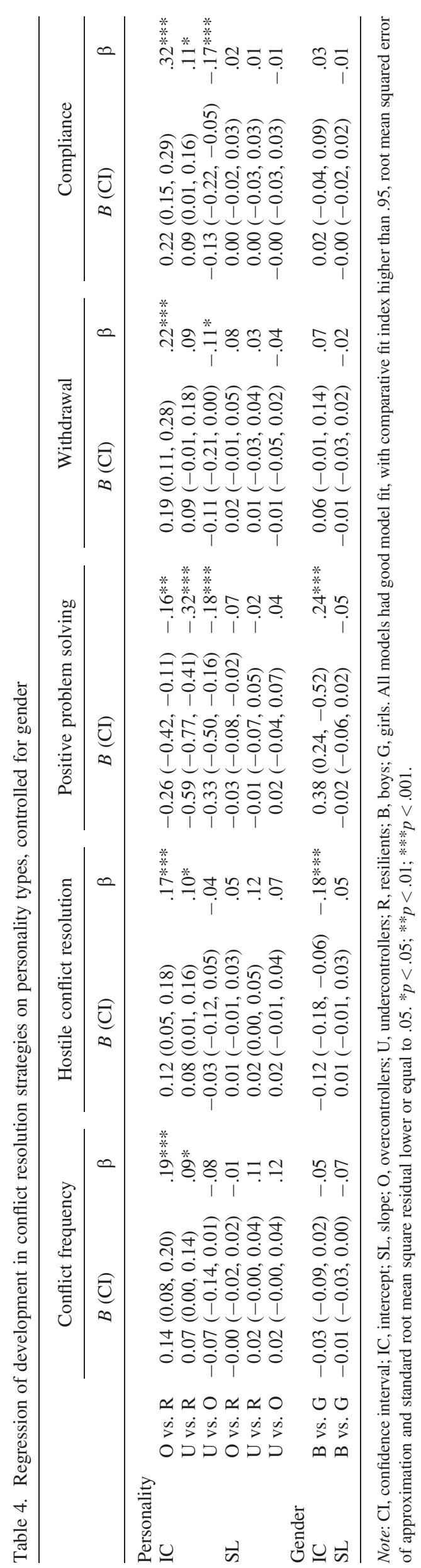

Copyright (C) 2013 John Wiley \& Sons, Ltd. 


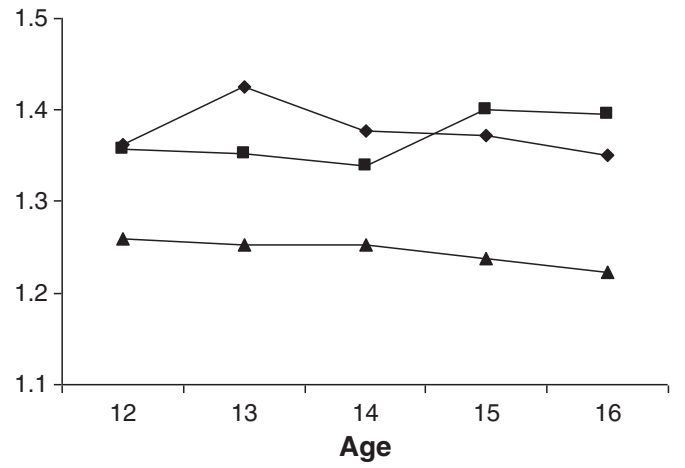

- Overcontrollers $\rightarrow-$ Undercontrollers $\_$Resilients

Note. The y-axis scale represented mean scores of conflict frequency. Item scale ranged from 1 to 5 .

Figure 1. Observed scores of developmental changes in adolescent conflict frequency. Note. The $y$-axis scale represented mean scores of conflict frequency. Item scale ranged from 1 to 5 .

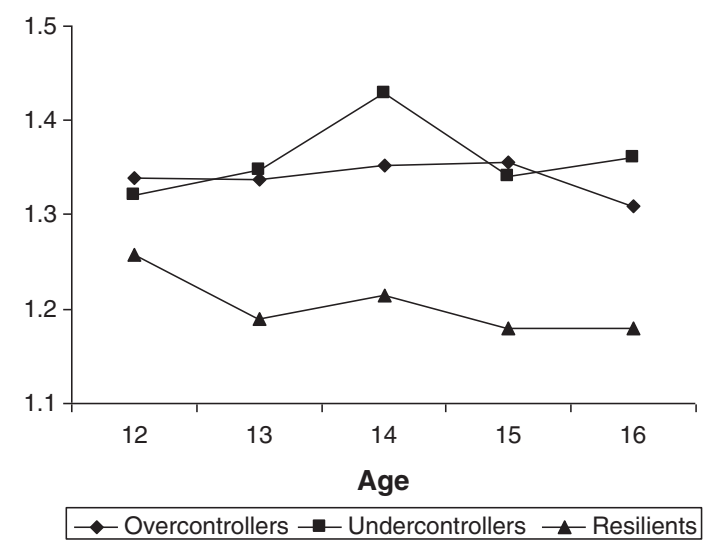

Note. The y-axis scale represented mean scores of hostile conflict resolution. Item scale ranged from 1 to 5 .

Figure 2. Observed scores of developmental changes in adolescent hostile conflict resolution. Note. The $y$-axis scale represented mean scores of hostile conflict resolution. Item scale ranged from 1 to 5 .

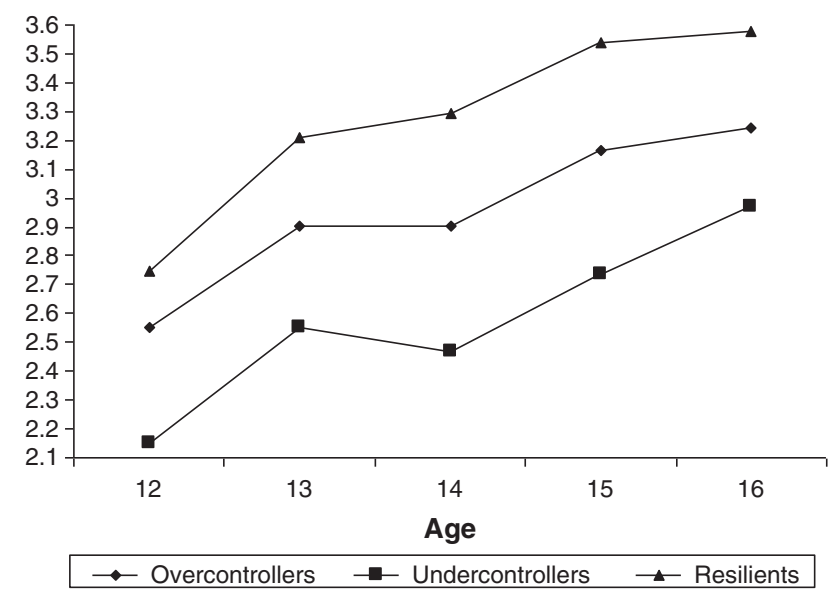

Note. The y-axis scale represented mean scores of positive problem solving. Item scale ranged from 1 to 5 .

Figure 3. Observed scores of developmental changes in adolescent positive problem solving. Note. The $y$-axis scale represented mean scores of positive problem solving. Item scale ranged from 1 to 5 .

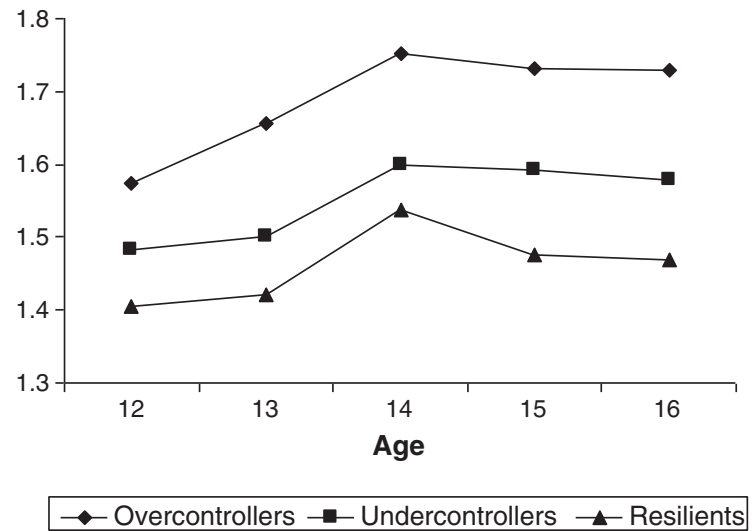

Note. The y-axis scale represented mean scores of withdraw. Item scale ranged from 1 to 5 .

Figure 4. Observed scores of developmental changes in adolescent withdrawal. Note. The $y$-axis scale represented mean scores of withdraw. Item scale ranged from 1 to 5 .

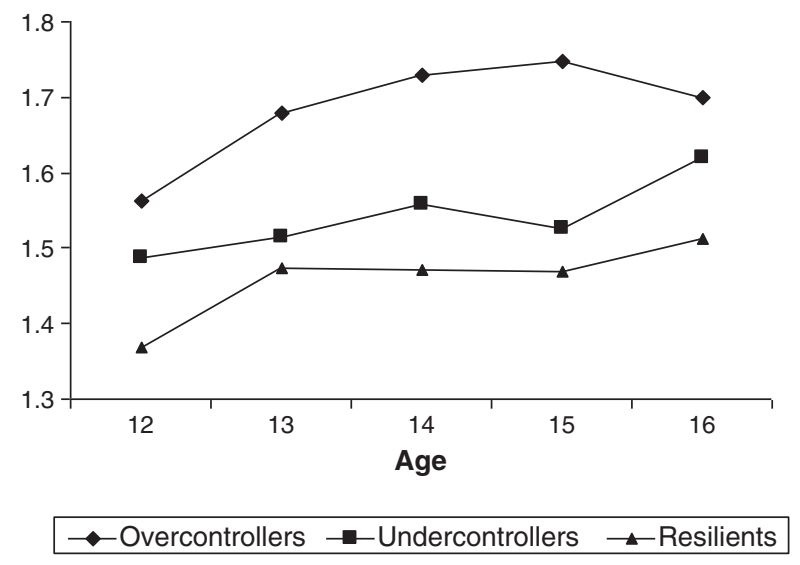

Note. The y-axis scale represented mean item of compliance. Item scale ranged from 1 to 5 .

Figure 5. Observed scores of developmental changes in adolescent compliance. Note. The $y$-axis scale represented mean item of compliance. Item scale ranged from 1 to 5 .

best friends from early to middle adolescence. We also investigated whether adolescents could be distinguished by different constellations of conflict resolution strategies. We further examined whether adolescents with different personality types differed in the mean levels and the developmental changes of conflict resolution strategies with best friends. In general, we found that adolescents' conflict frequency and hostile conflict resolution with their best friends did not change, whereas their use of positive problem solving, withdrawal, and compliance increased across the years. We identified three conflict resolution types based on constellations of the four conflict resolution strategies, which we labelled the no-resolution type, ambivalent conflict resolution type, and positive conflict resolution type. Moreover, we found that adolescents with different personality types differed in the levels of conflict resolution strategies with best friends and also were distinct on the distribution on the three conflict resolution types. 
Table 5. Distribution of adolescents with different personality types in different conflict resolution types

\begin{tabular}{|c|c|c|c|c|c|c|}
\hline & & & \multicolumn{4}{|c|}{ Conflict resolution types } \\
\hline & & & $\begin{array}{l}\text { Ambivalent conflict } \\
\text { resolution type }\end{array}$ & No-resolution type & $\begin{array}{l}\text { Positive conflict } \\
\text { resolution type }\end{array}$ & Total \\
\hline \multirow[t]{10}{*}{ Personality types } & \multirow[t]{3}{*}{$\mathrm{O}$} & Count (\% of total) & $96(10.41)$ & $132(14.32)$ & $154(16.70)$ & \multirow[t]{3}{*}{$382(41.43)$} \\
\hline & & Expected count & 72.51 & 151.64 & 157.85 & \\
\hline & & Adjusted residual & 4.01 & -2.68 & -0.52 & \\
\hline & \multirow[t]{3}{*}{$\mathrm{U}$} & Count (\% of total) & $56(6.07)$ & $120(13.02)$ & $52(5.64)$ & \multirow[t]{3}{*}{$228(24.73)$} \\
\hline & & Expected count & 43.28 & 90.51 & 94.22 & \\
\hline & & Adjusted residual & 2.48 & 4.60 & -6.54 & \\
\hline & \multirow[t]{3}{*}{$\mathrm{R}$} & Count (\% of total) & $23(2.49)$ & $114(12.36)$ & $175(18.98)$ & \multirow[t]{3}{*}{$312(33.84)$} \\
\hline & & Expected count & 59.22 & 123.85 & 128.93 & \\
\hline & & Adjusted residual & -6.43 & -1.40 & 6.51 & \\
\hline & Total & Count ( $\%$ of total) & $176(18.98)$ & $366(39.70)$ & $381(41.32 \%)$ & $922(100)$ \\
\hline
\end{tabular}

Note: O, overcontrollers; $\mathrm{U}$, undercontrollers; R, resilients.

\section{Development of Adolescents' Conflict Frequency and Conflict Resolution}

Adolescents' use of positive problem solving, withdrawal, and compliance increased from early to middle adolescence. These results are in accordance with theoretical ideas that due to the increasing salience and growing intimacy of friendship, as well as advanced cognitive ability during adolescence, youths' conflict resolution behaviour should increasingly reflect consideration of others' needs or careful awareness of potential friendship disruptions (Laursen et al., 2001; Laursen \& Pursell, 2008; Selfhout et al., 2009). Findings are also in line with cross-sectional results indicating agerelated increases in the use of positive problem solving and withdrawal (Laursen et al., 2001).

Unexpectedly, adolescents' conflict frequency and hostile conflict resolution remained stable from early to middle adolescence. These results are inconsistent with the theoretical notion that adolescents should have less conflict or use less hostile conflict resolution, which potentially threaten developing relationships (Laursen, 1998; Laursen \& Pursell, 2008). Our finding regarding hostile conflict resolution is also inconsistent with a previous meta-analytic review that compared cohorts of young adults, adolescents, and children, and suggested that there is lower use of this strategy in older cohorts (Laursen et al., 2001). The reason we found stable conflict frequency and hostile conflict resolution in this longitudinal study might be attributable to a floor effect, as the levels for these two aspects were already very low among our sample. It might also be that the decrease occurs already in earlier ages, such as childhood, or that the age range in our study of adolescents was not sufficiently large to detect the changes.

\section{Conflict Resolution Typology}

Through a person-centred approach, we identified three conflict resolution types based on the constellations of different conflict resolution strategies. These findings indicate that different conflict resolution strategies are not used in isolation, but instead are combined to form certain patterns. For instance, we found that utilizations of hostile conflict resolution, withdrawal, and compliance were likely to go hand-in-hand. The simultaneously low or high levels of these three conflict resolution strategies help to distinguish adolescents with an ambivalent conflict resolution type from those with no-resolution and positive conflict resolution types. These latter types were further differentiated by low versus high levels of positive problem solving, respectively.

Further, adolescents with different conflict resolution types reflected different combinations of concern for self and others (Pruitt \& Carnevale, 1993). Adolescents with a positive conflict resolution type adopted mainly positive problem solving that reflects a high and balanced concern of both self and other. Adolescents with a no-resolution conflict type scored low in all conflict resolution strategies, indicating a low concern for both self and others. Adolescents belonging to the ambivalent conflict resolution type used intermediate levels of positive problem solving and scored highest on hostile conflict resolution, compliance, and withdrawal. This pattern suggests imbalance and vacillation in concerns for self and others, in which youths switch between expressing high concern for themselves and low concern for the other versus high concern for the other and low concern for themselves. Adolescents belonging to the ambivalent type may have difficulties with establishing a balance between interdependence and individuality, which is a crucial developmental task in adolescent friendships (Selman, 1990; Sullivan, 1953). These youths may resemble the disengaged friendship type distinguished by Shulman and Laursen (2002), which is characterized by low levels of interdependence and low levels of individuality. In contrast, adolescents classified within the positive conflict resolution type may resemble interdependent friendships, which have high and balanced concern for self and others and use more positive conflict resolution with friends during conflict (Selfhout et al., 2009). However, future studies are needed to test this assumption.

In this study, the majority of adolescents belonged either to the no-resolution or the positive conflict resolution types, within which they employed strategies aimed at mitigating conflict intensity. In addition, we did not find adolescents with conflict resolution types reflecting high concern for self and low concern for others. Namely, when adolescents in conflict with their best friends, they typically did not use 
hostile conflict resolution strategy alone. These findings may reflect adolescents' appreciation that it is important to preserve interpersonal bonds, and their sensitivity to potential costs of conflict in voluntary and potentially unstable relationships such as friendships. These features might promote their endeavour to minimize negative conflict outcomes and resolve conflict in a non-aggressive manner. They try to handle conflict with a minimum use of hostile conflict resolution strategy or avoid the use of a hostile conflict resolution strategy alone (Laursen et al., 2001; Laursen, Hartup, \& Koplas, 1996). Moreover, there was no conflict resolution type reflecting high concern for others and low concern for self. In another word, adolescents did not predominantly adopt compliance as a conflict resolution strategy in conflict with their best friends. The reason might be that although compliance belongs to one of the non-aggressive conflict resolution strategies that would not end a relationship in a short term, using compliance alone during conflict might not be beneficial for the maintenance of a friendship, because using too much compliance is not in agreement with the increasing equality in adolescent friendships (De Goede et al., 2009).

\section{Role of Personality Types in Adolescents' Conflict Resolution}

This study provided support for our hypothesis regarding the association between personality types and conflict resolution with friends, by showing that individuals with different personality types differed both in the levels of conflict resolution strategies and in their differential distributions on conflict resolution types. During conflict with best friends, resilients used the most positive problem solving, the least hostile conflict resolution and compliance, and also had low withdrawal. This is in agreement with resilients' typical characteristics, such as high agreeableness, emotional stability, and social potency (e.g. assertive, leadership ability), and low social withdrawal (Asendorpf \& Van Aken, 1999; Caspi \& Silva, 1995; Klimstra et al., 2010). Undercontrollers endorsed the least positive problem solving, had low withdrawal and high hostile conflict resolution, and had median levels of compliance. These results are partly in line with our expectations, given undercontrollers' lower agreeableness, withdrawal, and higher aggressiveness (Asendorpf \& Van Aken, 1999; Klimstra et al., 2010). Their compliant behaviour, which was unexpected, might be attributable to their lower social skills, which could preclude them from persuading their friends in conflict and eventually lead to compliance (Caspi \& Silva, 1995). In addition, overcontrollers used the most withdrawal and compliance, but surprisingly, had high levels of hostile conflict resolution that were comparable to undercontrollers. Their withdrawal behaviour and 'follower' position during conflict concur with overcontrollers' characteristics such as keeping thoughts and feelings to themselves, and being obedient in social situations (Asendorpf \& Van Aken, 1999; Hart et al., 1997). Although prior research has suggested that highly agreeable individuals are less likely to employ a hostile conflict resolution (Gunthert et al., 1999), overcontrollers' higher levels of hostile conflict resolution strategy could be explained by their relatively lower emotional stability (Klimstra et al., 2010), which might provoke negative strategies (e.g. hostility) during conflict (Gunthert et al., 1999).

The differential levels of conflict resolution strategies among adolescents with different personality types have some implications in practice. Overcontrollers' and undercontrollers' higher compliance and/or withdrawal behaviours and lower positive problem-solving strategies than resilients might imply that interventions aiming at improving overcontrollers' and undercontrollers' positive problem-solving strategies might help to decrease their withdrawing and compliant behaviours during conflict with their best friends.

Further, findings revealed that adolescents with different personality types differed in the distribution on conflict resolution types. In addition, conflict frequency with best friends was distinguishable by both personality types and conflict resolution types. In particular, both overcontrollers and undercontrollers had more conflict with their best friends than resilients, and both groups were more likely than expected to belong to the ambivalent conflict resolution type. Resilients, on the other hand, had the least conflict with their best friends and were under-represented within the ambivalent conflict resolution type, but over-represented within the positive conflict resolution type. In addition, adolescents belonging to the ambivalent conflict resolution type had more conflict than did the other two types across the years. Together, these findings suggest that adolescents' personality types might underlie their use of particular conflict resolution behaviours (Wilmot \& Hocker, 2001). Additionally, the results imply that the ambivalent conflict resolution type might play a role in high conflict frequency within friendships, or vice versa.

In addition, although overcontrollers and undercontrollers consistently have a higher conflict frequency than resilients, they all scored relatively low. Across early to middle adolescence, adolescents with different personality types had about one conflict with best friends per week. This finding further confirms previous studies' proposal that adolescents generally try to avoid conflict in order to maintain their friendship (Collins \& Steinberg, 2006; Van Doorn, Branje, Hox, \& Meeus, 2009).

\section{Limitations, Strengths, and Future Research Directions}

Some limitations of this study need to be recognized. First, we focused on a restricted age range of participants, from early to middle adolescence. It would be more informative to also include data from late adolescence so that we could have a picture of developmental changes for the whole of adolescence. Second, data were derived from adolescents' self-reports, and prior studies suggest that results from selfreported data are discrepant from observational data; positive problem solving tends to be higher in self-reports, especially when the participants are relatively young (Laursen et al., 2001). Another limitation lies in the use of single-informant data, which might introduce reporter bias, because conflicts are dyadic interactions during which the other person's behaviour is an important factor to consider (Park \& Antonioni, 2007). These limitations, to some extent, restrict 
the generalizability of our findings. Future work should aim to use a combination of self-reports, observational approaches, and multiple informants, as well as assess longer periods of adolescence.

Despite these limitations, this study is the first attempt to examine the developmental changes in adolescents' conflict frequency and conflict resolution with friends, and thus contributes to a more comprehensive understanding of agerelated shifts in these behaviours. In addition, the current study is the first to document that adolescents with different personality types differed in their conflict frequency and conflict resolution with friends.

In conclusion, this study showed developmental changes in adolescents' conflict frequency and conflict resolution from early to middle adolescence. Across this period, adolescents develop an increasingly mature manner in conflict resolution with best friends. Moreover, both variable-centred and person-centred approaches confirmed a link between conflict resolution and personality types.

\section{REFERENCES}

Asendorpf, J. B., \& Van Aken, M. A. G. (1999). Resilient, overcontrolled, and undercontrolled personality prototypes in childhood: Replicability, predictive power, and the trait-type issue. Journal of Personality and Social Psychology, 77, 815-832.

Berndt, T. B., \& Perry, T. G. (1986). Children's perceptions of friendships as supportive relationships. Developmental Psychology, 22, 640-648.

Block, J. H., \& Block, J. (1980). The role of ego-control and egoresiliency in the organization of behavior. In W. A. Collins (Ed.), Development of cognition, affect, and social relations. Hillsdale: Lawrence Erlbaum Associates.

Bollen, K. A. (1989). Introduction to structural equation models with latent variables. New York: Wiley.

Bowker, A. (2004). Predicting friendship stability during early adolescence. Journal of Early Adolescence, 24, 85-112.

Branje, S. J. T., Van Doorn, M., Van der Valk, I., \& Meeus, W. H. J. (2009). Parent-adolescent conflict, conflict resolution types, and adolescent adjustment. Journal of Applied Developmental Psychology, 30 195-204.

Branje, S. J. T., Van Lieshout, C. F. M., \& Gerris, J. R. M. (2007). Big Five personality development in adolescence and adulthood. European Journal of Personality, 21, 45-62.

Brown, B. (2004). Adolescents' relationships with peers. In R. Lerner \& L. Steinberg (Eds.), Handbook of adolescent psychology. 363-394. New York: Wiley.

Caspi, A. (2000). The child is father of the man: Personality continuities from childhood to adulthood. Journal of Personality and Social Psychology, 78, 158-172.

Caspi, A., \& Silva, P. A. (1995). Temperamental qualities at age three predict personality traits in young adulthood: Longitudinal evidence from a birth cohort. Child Development, 66, 486-498.

Collins, W. A., \& Steinberg, L. (2006). Adolescent development in interpersonal context. In W.Damon \& N. Eisenberg (Eds.), Handbook of child psychology: Vol. 4, Socioemotional processes (pp. 1003-1067). New York: Wiley.

De Goede, I. H. A., Branje, S. J. T., \& Meeus, W. H. J. (2009). Developmental changes and gender differences in adolescents' perceptions of friendships. Journal of Adolescence, 32, 1105-1123.

Denissen, J. A., Asendorpf, J. B., \& Van Aken, M. A. G. (2007). Childhood personality predicts long-term trajectories of shyness and aggressiveness in the context of demographic transitions in emerging adulthood. Journal of Personality, 76, 68-99.
Donnellan, M. V., \& Robins, R. W. (2010). Resilient, overcontrolled, and undercontrolled personality types: Issues and controversies. Social and Personality Psychology Compass, 4, 1070-1083.

Duncan, T. E., Duncan, S. C., Strycker, L. A., Li, F., \& Alpert, A. (1999). An introduction to latent variable growth curve modeling. Mahwah, NJ: Erlbaum.

Dunn, J. (1993). Young children' close relationships: Beyond attachment. Newbury Park, CA: Sage.

Enders, C. K., \& Bandalos, D. L. (2001). The relative performance of full information maximum likelihood estimation for missing data in structural equation models. Structural Equation Modeling, 8, 430-457.

Furman, W., \& Buhrmester, D. (1992). Age and sex differences in perceptions of networks of personal relationships. Child Development, 63, 103-115.

Garaziano, W. G., Jensen-Campbell, L. A., \& Hair, E. C. (1996). Perceiving interpersonal conflict and reacting to it: The case of agreeableness. Journal of Personality and Social Psychology, $70,820-835$.

Goldberg, L. R. (1992). The development of markers for the BigFive factor structure. Psychological Assessment, 4, 26-42.

Gunthert, K. C., Cohen, L. H., \& Armeli, S. (1999). The role of neuroticism in daily stress and coping. Journal of Personality and Social Psychology, 77, 1087-1100.

Haberman, S. J. (1973). The analysis of residuals in cross-classified tables. Biometrics, 29, 205-220.

Hart, D., Hoffman, V., Edelstein, W., \& Keller, M. (1997). The relation of childhood personality types to adolescent behavior and development: A longitudinal study of Icelandic children. Developmental Psychology, 33, 195-205.

Hartup, W. W. (1993). Adolescents and their friends. In B. Laursen (Ed.), Close friendships during adolescents: New directions for child development. 3-22. San Francisco: Jossey-Bass.

Hix-Small, H., Duncan, T. E., Duncan, S. C., \& Okut, H. (2004). A multivariate associative finite growth mixture modeling approach examining adolescent alcohol and marijuana use. Journal of Psychopathology and Behavioral Assessment, 26, 255-270.

Hu, L. T., \& Bentler, P. M. (1999). Cutoff criteria for fit indexes in covariance structure analysis: Conventional criteria versus new alternatives. Structure Equation Modeling, 6, 1-55.

Jensen-Campbell, L. A., \& Graziano, W. G. (2001). Agreeableness as a moderator of interpersonal conflict. Journal of Personality, 69, 323-361.

Jensen-Campbell, L. A., Graziano, W. G., \& Hair, E. C. (1996). Personality and relationships as moderators of interpersonal conflict in adolescence. Merrill-Palmer Quarterly, 42, 148-164.

Klimstra, T. A., Hale III, W. W., Raaijmakers, Q. A. W., Branje, S. J. T., \& Meeus, W. H. J. (2010). A developmental typology of adolescent personality. European Journal of Personality, 24, 309-323.

Kline, R. B. (2005). Principles and practice of structural equation modeling. New York: The Guilford Press.

Kurdek, L. A. (1994). Conflict resolution styles in gay, lesbian, heterosexual nonparent, and heterosexual parent couples. Journal of Marriage and Family, 56, 705-722.

Laursen, B. (1993). The perceived impact of conflict on adolescent relationships. Merrill-Palmer Quarterly, 39, 535-550.

Laursen, B. (1998). Closeness and conflict in adolescent peer relationships: Interdependence with friends and romantic partners. In W. M. Bukowski, A. F. Newcomb \& W. W. Hartup (Eds.), The company they keep: Friendship in childhood and adolescence. 186-210. New York: Cambridge University Press.

Laursen, B., \& Pursell, G. (2008). Conflict in peer relationships. In K. H. Rubin (Ed.), Handbook of peer interactions, relationships and groups. 267-286. New York: Guilford Press.

Laursen, B., Finkelstein, B. D., \& Betts, N. T. (2001). A developmental meta-analysis of peer conflict resolution. Development Review, 21, 423-449.

Laursen, B., Hartup, W. W., \& Koplas, A. (1996). Towards understanding peer conflict. Merrill-Palmer Quarterly, 42, 76-102. 
Little, R. J. (1988). A test of missing completely at random for multivariate data with missing values. Journal of the American Statistical Association, 83, 1198-1202.

Lo, Y., Mendell, N. R., \& Rubin, D. B. (2001). Testing the number of components in a normal mixture. Biometrika, 88, 767-778.

Meeus, W. H. J., Akse, J., Branje, S. J. T., Ter Bogt, T. F. M., Crommelin, P. M., Delsing, M. J. M. H., et al. (2006). Codebook of the research project CONflict And Management Of Relationships (CONAMORE). Unpublished manuscript, Utrecht University, The Netherlands, 2006.

Meeus, W., Van de Schoot, R., Klimstra, T., \& Branje, S. (2011). Personality types in adolescence: Change and stability and links with adjustment and relationships: A five-wave longitudinal study. Developmental Psychology, 47, 1181-1195.

Mervielde, I., \& Asendorpf, J. B. (2000). Variable-centered and person-centered approaches to childhood personality. In S. Hampson (Ed.), Advances in personality psychology. 37-76. London: Routledge.

Moskowitz, D. S., \& Coté, S. (1995). Do interpersonal traits predict affect? A comparison of three models. Journal of Personality and Social Psychology, 69, 915-924.

Muthén, B. O., \& Muthén, L. K. (2000). Integrating personcentered and variable-centered analyses: Growth mixture modeling with latent trajectory classes. Alcoholism, Clinical and Experimental Research, 24, 882-891.

Muthén, L. K., \& Muthén, B. O. (2010). Mplus user's guide (6th ed). Los Angeles, CA: Muthén \& Muthén.

Nagin, D. S. (2005). Group-based modeling of development. Cambridge, MA: Harvard University.

Newman, D. L., Caspi, A., Moffitt, T. E., \& Silva, P. A. (1997). Antecedents of adult interpersonal functioning: Effect of individual difference in age 3 temperament. Developmental Psychology, 33, 206-217.

Park, H., \& Antonioni, D. (2007). Personality, reciprocity and strength of conflict resolution strategy. Journal of Research in Personality, 41, 110-125.

Pruitt, D. G., \& Carnevale, P. J. (1993). Negotiation in social conflict. Pacific Grove, CA: Brooks/Cole.

Raftery, A. E. (1993). Bayesian model selection in structural equation models. In Testing structural equation models (pp. 163-180). Beverly Hills, CA: Sage.

Robins, R. W., John, O. P., Caspi, A., Moffitt, T. E., \& StouthamerLoeber, M. (1996). Resilient, overcontrolled, and undercontrolled boys: Three replicable personality types. Journal of Personality and Social Psychology, 70, 157-171.

Sandy, S. V., \& Cochran, K. (2000). The development of conflict resolution skills in children: Preschool to adolescence. In M. Deutsch \& P. Coleman (Eds.), The handbook of conflict resolution: Theory and practice. San Francisco: Jossey-Bass.

Scholte, R. H. J., Van Lieshout, C. F. M., De Wit, C. A. M., \& Van Aken, M. A. G. (2005). Adolescent personality types and subtypes and their psychosocial adjustment. Merrill-Palmer Quarterly, 51, 258-286.

Schwarz, G. (1978). Estimating the dimension of a model. The Annals of Statistics, 6, 461-464.

Selfhout, M. H. W., Branje, S. J. T., \& Meeus, W. H. J. (2009), Developmental trajectories of perceived friendship intimacy, constructive problem solving, and depression from early to late adolescence. Journal of Abnormal Child Psychology, 37, 251-264.

Selman, R. L. (1990). Fostering intimacy and autonomy. In W. Damon (Ed.), Child development today and tomorrow. 409-435. San Francisco: Jossey-Bass.

Shulman, S., \& Knafo, D. (1997). Balancing closeness and individuality in adolescent close relationships. International Journal of Behavioral Development, 21, 687-702.

Shulman, S., \& Laursen, B. (2002). Adolescent perceptions of conflict in interdependent and disengaged friendships. Journal of Research on Adolescence, 12, 353-372.

Statistics Netherlands. (2008). Statline: Bevolking naar Herkomst en Generatie. Voorburg, The Netherlands: Statistics Netherlands.

Sullivan, H. S. (1953). The interpersonal theory of psychiatry. Oxford, England: Norton \& Co.

Van Doorn, M. D., Branje, S. J.T., Hox, J. J., \& Meeus, W. H. J. (2009). Intraindividual variability in adolescents' perceived relationship satisfaction: The role of daily conflict. Journal of Youth and Adolescence, 38, 790-803.

Van Doorn, M. D., Branje, S. J. T., \& Meeus, W. H. J. (2007). Longitudinal transmission of conflict resolution styles from marital relationships to adolescent-parent relationships. Journal of Family Psychology, 21, 426-434.

Vermulst, A. A., \& Gerris, J. R. M. (2005). QBF: Quick Big Five persoonlijkheidstest handleiding [Quick Big Five personality test manual]. Leeuwarden, The Netherlands: LDC Publications.

Wilmot, W., \& Hocker, J. (2001). Interpersonal conflict (6th ed). Boston: McGraw-Hill. 